\title{
Optimized Design of a Bagasse Dryer System for Sugar Industry
}

\author{
L. Praveen Raj and B. Stalin
}

\begin{abstract}
Bagasse is used as one of the fuels for boilers to generate power in most of the sugar industries all over the world. Bagasse consists of moisture which affects the efficiency of the boiler which in turn reduces the power output. This paper investigates about the use of pneumatic dryer system with number of steel pipes in it,within which hot steam is used as the medium for drying. Modifications in pre-existing design of the dryer such as dimension, capacity, operating temperature, working pressure and heating surface area were considered. Analytical calculations and thermal analysis has been carried out to determine the percentage reduction of moisture. Optimization has been carried out using Taguchi's technique. Parameters such as pressure, temperature and mass flow rate of the hot steam were taken into account for optimization.The work shows that 5\% increase in the reduction of moisture in bagasse leads to 7\% increase in boiler efficiency and 5\% increase in power output.
\end{abstract}

Keywords--- Bagasse, Moisture Content, Pneumatic Dryer, Boiler Efficiency, Taguchi's Technique.

\section{INTRODUCTION}

B AGASSE is the residual fibre that remains after the crushing of cane. It consist of water(moisture), fibre and small amount of soluble solids.Bagasse represents $12 \%$ of the total sugarcane mass. The cane, after being cut, crushed in conventional and non conventional mills in a sugar industry leaves moist bagasse. The bagasse is sometimes postprocessed for other industrial applications like paper industries and bagasse is even used as a reinforcement fiber in composites. In some sugar industries around the world, the bagasse is used for power production. The investigation was carried out in "Sakthi Sugars", Padamathur, Tamilnadu, India, where a half of the total bagasse obtained is used for power production for their self-consumption. As observed, the average moisture content in the bagasse is between $50.18 \%$ $52.30 \%$. With this percentage of the moisture content, the efficiency of the boiler is about $70.86 \%$. The power output is about $17.5 \mathrm{Kw}$. In 1990, Professor Kerr investigated about drying bagasse. The cross section of the dryer is about $1.2 \mathrm{~m} \mathrm{x}$ $1.8 \mathrm{~m}$. The height of the boiler is about $6 \mathrm{~m}$. He used a boiler made of steel. He observed a reduction of moisture from $54.3 \%$ to $46.4 \%$ (wet bagasse). As a result, steam production was increased. In 1991, Kinoshita designed a system consisting of four chambers. He used flue gas of the boiler for drying the bagasse.

L. Praveen Raj, PG Scholar, Department of Mechanical Engineering, Anna University, Regional Campus, Madurai, Tamilnadu, India. E-mail:l.praveenrajbe@gmail.com

B. Stalin, Assistant Professor, Department of Mechanical Engineering, Anna University, Regional Campus, Madurai, Tamilnadu, India. DOI:10.9756/BIJIEMS.7536
Three of the four installations were rotary dryers and the other, a flash dryer. In 1983, Correia designed a pneumatic transport dryer. He reported an increase in steam production of $16 \%$ by drying the bagasse from $52 \%$ to $40 \%$ moisture (w.b.). Cárdenas et al. (1994) described a pneumatic dryer. They studied the energetic efficiency of a boiler-dryer system. They concluded that the use of a dryer improves the boiler efficiency. This work presents the investigation and optimization of the bagasse drying system for an efficient maximization of steam generation and power production.

Table 1: Boiler Specifications

\begin{tabular}{|l|l|}
\hline \multicolumn{2}{|l|}{ BOILER SPECIFICATIONS } \\
\hline Type & Water tube boiler \\
\hline Capacity & 135 ton. \\
\hline Working Pressure & $110 \mathrm{bar}$ \\
\hline Temperature & $540 \pm 5^{\circ} \mathrm{C}$ \\
\hline Boiler Exhaust & $3 \mathrm{~kg} / \mathrm{cm}^{2}$ or 40 (pounds or lbs) \\
\hline Heating Surface area & 8709 sq. $\mathrm{m}$ \\
\hline Steam level & $60-70$ ton steam \\
\hline
\end{tabular}

Bagasse Specifications

\begin{tabular}{|l|l|}
\hline \multicolumn{2}{|l|}{ BAGASSE SPECIFICATIONS } \\
\hline Moisture & $46 \%-52 \%$ \\
\hline Fibre (including ash) & $43 \%-52 \%$ \\
\hline Soluble solids & $2 \%-6 \%$ \\
\hline Average Density & $150 \mathrm{~kg} / \mathrm{m} 3$ \\
\hline Low Heat Value & $1780 \mathrm{kcal} / \mathrm{kg}$ \\
\hline High Heat Value & $4,000 \mathrm{kcal} / \mathrm{kg}$ \\
\hline
\end{tabular}

Apart from those tabulated, other properties of bagasse are: Fibre consists of cellulose-27\%, Pentosans-30\%, Lignin- 20\%, Ash-3\%, Gross Calorific Value $=4600-12 \mathrm{~S}-46 \mathrm{~W}(\mathrm{KJ} / \mathrm{kg})$, Net Calorific Value $=4250-12 \mathrm{~S}-48.5 \mathrm{~W}(\mathrm{KJ} / \mathrm{kg})$.

\section{BAGASSE DRYER SYSTEM}

Drying generally refers to the removal of moisture from a solid by evaporation. Based on the mode of heat transfer, the bagasse dryer system can be broadly classified into two types namely:

- Indirect dryers

- $\quad$ Direct dryers

The proposed system is an indirect type dryer

\section{A. Indirect Dryers}

In an Indirect type dryer, a metal wall divide the product and the heat transfer medium.The heat transfer is only through conduction and forced convection. This method can be adopted for low pressure steam bagasse which ranges about $3 \mathrm{~atm}$ or less. It is made by inserting large tube bundles in a large bin. Typically, the bagasse moisture can be reduced from 50\% to $45 \%$. 


\section{B. Dryer Design}

In a rotary dryer, material is fed into a slowly rotating cylinder. The feedstock is lifted and cascaded down through the drying medium by the longitudinal flights inside the cylinder. Pipes with diameter ranging from $100-150 \mathrm{~mm}$ are placed vertically in the large bin.the pipes passes along the vertical axis. The pitch of the vertical axis ranges between 450-600 $\mathrm{mm}$. The vertical steam pipes of the above mentioned dimension are lined along the circumference of the bin. The low pressure steam is fed to the individual pipes from the top. This is attained by a common feed header with radial outlets.

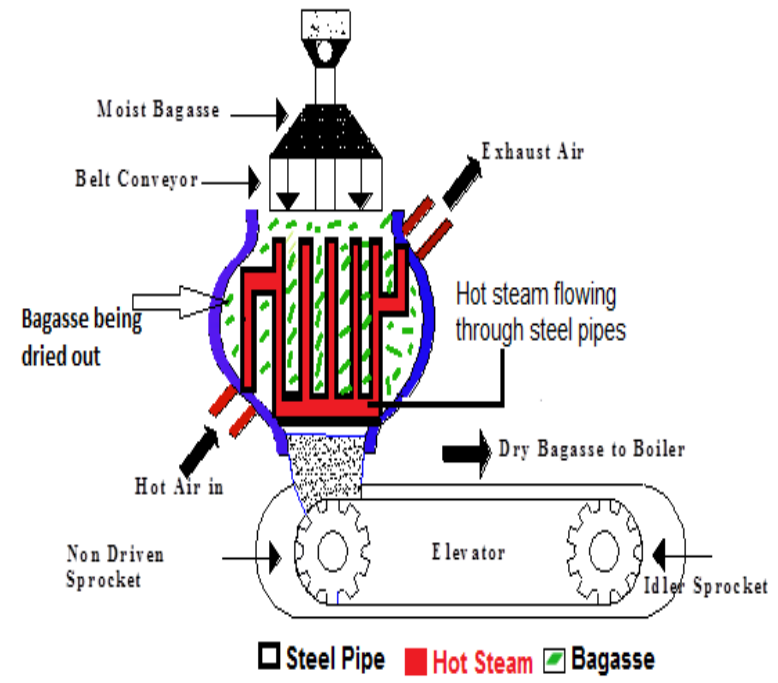

Figure 1: Bagasse Dryer System

The removal of the condensate out of the system is achieved by connecting the pipes together at the bottom end. The bagasse is made to flow from the top of the dryer. The moist bagasse travels down vertically to the bottom, where and when it makes a physical contact with the steel pipes in which hot steam is flowing. The moisture content is removed by liberating the water vapour to the top of the bin.

\section{Boiler Description}

This paper work has been carried out in a sugar industry. Hence the datas presented here are as observed from the industry.The reason for presenting this information about the boiler helps in understanding the calculations.

The boiler used in the industry is a drum type water tube boiler.Vertical arrangement of the steam generation tube is placed between two drums. The vertical centre line between the two drums is $9.95 \mathrm{~m}$. Super heater is arranged in front of the boiler bank and is screened from the furnace by two rows of tubes. Boiler is designed for natural circulation of water and is of bottom-supported type. A balanced draught needs to be maintained inside the furnace, which is achieved by equipping the boiler with three draught fans namely, induced, forced and secondary air fans respectively. The air flow rate of the three draught fans are 3750,1500 and $460 \mathrm{~m}^{3} / \mathrm{min}$ respectively. The thermal efficiency of the boiler is enhanced by using economizer and air heater. Outgoing flue gases from the boiler at high temperature are utilized by such boiler accessories. The feed water pressure is maintained at 1.5 times the working pressure of the steam by a multistage centrifugal feed pump.
Steam rating of the boiler is about 60 tons/hr. The designed superheated steam pressure and temperature were $23 \mathrm{~kg} / \mathrm{cm}^{2}$ and $350^{\circ} \mathrm{C}$ respectively. Heating surface of boiler, super heater, air heater and economizer were found to be 1565, 115 and 1015 and $135 \mathrm{~m}^{2}$, respectively.

The furnace was a spreader stoker type with a volume of $254.5 \mathrm{~m}^{3}$ under the existing condition of the plant. Dumping grate area of the furnace was $251 \mathrm{~m}^{2}$ comprising of eight sections. Bagasse is supplied from the main carrier to the furnace by means of four rectangular cross sectional bagasse feeders.

\section{CALCULATIONS}

Under the mill working conditions, the average values were taken as:

- Moisture content of bagasse $(\mathrm{w})=50 \%$

- Sucrose in bagasse (s) $=3.0 \%$

Based on the formulae proposed by Hu-Got in 1986, the calorific values were calculated as follows:

Gross calorific value $(\mathrm{GCV})=8280(1-\mathrm{W})-2160 \mathrm{~S}$

Net calorific value $(\mathrm{NCV})=7650-8730 \mathrm{~W}-2160 \mathrm{~S}$

These equations for calculating GCV and NCV includes the latent heat of vaporization of water which is formed during combustion of hydrogen present in bagasse and the latent heat of vaporization of water content or the moisture content of the bagasse.

Bagasse Burnt in Terms of Standard Bagasse of 45\% Moisture Heat value of $1 \mathrm{~kg}$ of bagasse actually burnt

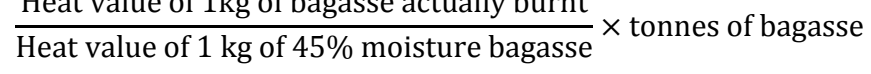

Total Fuel Burnt in Terms of Standard Bagasse of 45\% Moisture

Bagasse burnt into standard bagasse + All other fuel converted into standard bagasse

$1 \mathrm{~kg}$ coal $=2.5 \mathrm{~kg}$ bagasse, $1 \mathrm{~kg}$ wood $=1.25 \mathrm{~kg}$ bagasse, 1 lit furnace oil $=5 \mathrm{~kg}$ bagasse.

\section{Equivalent Evaporation}

Water evaporated from and at $100^{\circ} \mathrm{C}$ :

$$
\text { water evaporated } \times \frac{\mathrm{H}-\mathrm{h}}{539}
$$

Where, $\mathrm{H}$-Total heat in steam issuing from the boilers in $\mathrm{Kcal} / \mathrm{kg}$

$\mathrm{h}$-Total heat in feed water in $\mathrm{Kcal} / \mathrm{kg}$

Equivalent Evaporation Percentage Cane

$$
\frac{\text { Equivalent evaporation tonnes }}{\text { Tonnes of cane }} \times 100
$$

Equivalent Evaporation per $\mathrm{kg}$ of Standard Bagasse

$$
\begin{aligned}
& \text { 1. } \frac{\text { Equivalent evaporation }}{\text { Sq. } \mathrm{m} \text { of boiler heating surface } / \mathrm{hr}} \\
& \text { 2. } \frac{\text { Total equivalent evaporation in } \mathrm{kg}}{\text { Total heating time }}
\end{aligned}
$$




\section{A. Steam Obtainable per $\mathrm{kg}$ of Bagasse}

For fuel control purposes, it is necessary to work out the quantity of steam which can theoretically be obtained from the combustion of a known weight of bagasse and that actually obtained under the working conditions of the factory. It is determined by considering the fuel value of bagasse by taking the $\mathrm{C}, \mathrm{H}$ and $\mathrm{O}_{2}$ content.

$$
\begin{aligned}
& \text { Gross Calorific Value (G.C.V) } \\
& \text { G.C.V. }=8280(1-\mathrm{W})-2160 \mathrm{~S} \\
& =8280(1-0.50)-2160(0.03) \\
& =4075 \mathrm{BTU} / \mathrm{lb}
\end{aligned}
$$

Net Calorific Value (N.C.V)

$$
\begin{aligned}
& \text { N.C.V. }=7650-8730 \mathrm{~W}-2160 \mathrm{~S} \\
& =7650-8730(0.50)-2160(0.03) \\
& =3220 \mathrm{BTU} / \mathrm{Lb}
\end{aligned}
$$

\section{B. Steam Obtainable per $\mathrm{kg}$ of Bagasse}

For fuel control purposes, it is necessary to work out the quantity of steam which can theoretically be obtained from the combustion of a known weight of bagasse and that actually obtained under he working conditions of the factory.

\section{Steam Theoretically Obtained can be Calculated as Follows}

\section{Fuel Value of Bagasse}

An average value of $4640 \mathrm{Kcal} / \mathrm{kg}$ of bone dry bagasse may be taken:

\section{Products of Combustion}

$$
\begin{array}{ll}
\text { Dry bagasse: } & \mathrm{C}-46.5 \% \\
& \mathrm{H}-6.5 \% \\
& \mathrm{O}_{2}-46 \% \\
\mathrm{C}+\mathrm{O}_{2}=\mathrm{CO}_{2} \\
12+32=44
\end{array}
$$

That means, per $\mathrm{kg}$ of $\mathrm{C}, \mathrm{O}_{2}$ required will be

and $\mathrm{CO}_{2}$ will be

$$
\frac{32}{12}=2.67
$$

$$
\frac{44}{12}=3.67
$$

Per kg of $\mathrm{H}, \mathrm{O}_{2}$ required to form water will be $\mathrm{H}_{2}+\mathrm{O}=\mathrm{H}_{2} \mathrm{O}$

$2.016+16=18.016$ (or) per kg of $\mathrm{H}, \mathrm{O}_{2}$ required will be

$$
\frac{16}{2.016}=7.93 \mathrm{~kg}
$$

$\mathrm{H}_{2} \mathrm{O}$ formed will be $8.93 \mathrm{~kg}$. Hence $1 \mathrm{~kg}$ of dry bagasse of the above composition will then require:

$$
(0.465 \times 2.67)+(0.65 \times 7.93)=1.75 \mathrm{~kg} \text { of } \mathrm{O}_{2}
$$

As bagasse has $0.46 \mathrm{O}_{2}$ already, $1.75-0.46=1.29 \mathrm{~kg}$ of $\mathrm{O}_{2}$

As oxygen in air is $23 \%$ by weight, $1.29 \mathrm{~kg}$ of $\mathrm{O}_{2}$ will come from $5.6 \mathrm{~kg}$ of air and the producs of combustion from 1 $\mathrm{kg}$ of dry bagasse will be:
1. Due to CO: $(0.465 \times 3.67)=1.70 \mathrm{~kg}$ of CO2

2. Due to $\mathrm{H}:(0.65 \times 8.93)=0.58 \mathrm{~kg}$ of $\mathrm{H} 2 \mathrm{O}$

If air has $1 \%$ moisture, $0.56 \mathrm{~kg}$ air will contain $0.56 \mathrm{~kg}$ $\mathrm{H}_{2} \mathrm{O}$. Hence total $\mathrm{H}_{2} \mathrm{O}$ will be $0.58+0.56=0.636 \mathrm{~kg}$.

Nitrogen introduced with air will be 5.6 X $0.76=4.256 \mathrm{~kg}$ $\left(\mathrm{N}_{2}\right)$ being $76 \%$ by weight of air., An excess air has to be used for enuring proper combustion. The various products of combustion with excess air of about $50 \%, 75 \%, 100 \%$ will be as follows:

With Excess Air, Quantity of H2O, N2, O2 will Increase

With $50 \%$ excess air quantity is $5.6+2.8=8.4 \mathrm{~kg}$

Moisture $=0.084$

Total $\mathrm{H}_{2} \mathrm{O}$ will bee $0.58+0.84=0.664$

If bagasse has $45 \%$ moisture, then $55 \%$ dry matter has:

1. C will be $-0.465 \times 0.55=0.256$

2. $\mathrm{H}_{2}$ will be $-0.65 \times 0.55=0.357$

3. $\mathrm{O}_{2}$ will be $-0.46 \times 0.55=0.253$

Now $\mathrm{C}$ to form $\mathrm{CO}_{2}$ will require $0.256 \times 7.93 \mathrm{O}_{2}$

$\mathrm{H}$ to form water will require $0.357 \mathrm{X} 7.93=0.283 \mathrm{O}_{2}$

Total oxygen required will be $0.683+0.283=0.966 \mathrm{~kg}$

$0.253 \mathrm{O}_{2}$ is already present in air hence $0.966-0.253=0.713$ which gives:

$$
\frac{0.713 \times 100}{23}=3.1 \mathrm{~kg} \text { of air }
$$

\section{Theoritcal Quantity of Steam Obtainable from Bagasse Having 45\% Moisture}

- On basis of air at $27^{\circ} \mathrm{C}$ and fuel gas temperature at $260^{\circ} \mathrm{C}$ the steam available (from at $100^{\circ} \mathrm{C}$ ) can be worked out as follows:

- It is accepted that each $\mathrm{kg}$ of water \% in the flue gas whether due to associated water or combined water about $694 \mathrm{k} . c a l$ of heat and each $\mathrm{kg}$ of gas whether $\mathrm{CO}_{2}$ or nitrogen or $\mathrm{O}_{2}$ about $55.56 \mathrm{k}$.cal of heat.

- Then heat loss due to associated water will be $0.45 \mathrm{X}$ $694=312 \mathrm{k} . c a l$ and that due to combined water 0.32 X $694=222$ k.cal.

1. With $50 \%$ excess air heat loss in gases will be:

$\mathrm{CO}_{2}=0.94$

$$
\begin{aligned}
& \mathrm{N}=3.53 \\
& =0.36 \\
& \text { Total }=4.83 \text { X } 55.56=268 \text { k.cal } .
\end{aligned}
$$

Total heat loss in water and gases will be:

$$
312+222+268==802 \mathrm{k} . \mathrm{cal} \text {. }
$$

2. With $75 \%$ of excess air heat losses in gases will be:

$$
\begin{aligned}
& \mathrm{CO}_{2}=0.94 \\
& \mathrm{~N}=4.122 \\
& \mathrm{O}=0.534 \\
& \text { Total }=5.596
\end{aligned}
$$

Heat loss will be 5.596 X $55.56=311$ k.cal. and toal loss in flue gas will be

$$
312+222+311=845 \mathrm{k} . \mathrm{cal} .
$$


3. Similarly with $100 \%$ excess air, heat losses in gases will be:

$$
\begin{aligned}
& \mathrm{CO}_{2}=0.94 \\
& \mathrm{~N}=4.712 \\
& \mathrm{O}=0.713
\end{aligned}
$$

Total $=6.365$ X $55.56=354$ k.cal.

Total heat loss $=312+222+354=888 \mathrm{k} . c a l$.

Now fuel value of bone dry bagasse may be taken as 4640 k.cal. that for $45 \%$ of moist bagasse or $55 \%$ of dry matter will be 4640 X $0.55=2552$ k.cal.

Then heat available for steam production in above cases viz. 50\%, 75\%, 100\% excess air will be:

$$
\begin{aligned}
& 50 \% \text { excess air }=2532-802=1750 \text { k.cal. } \\
& 75 \% \text { excess air }=2532-845=1707 \text { k.cal. } \\
& 100 \% \text { excess air }=2532-888=1664 \text { k.cal. }
\end{aligned}
$$

Now latent heat of steam being 539k.cal., steam obtainable per kg of bagasse will be respectively:

$$
\begin{aligned}
& \frac{1750}{530}=8.25 \mathrm{~kg} \\
& \frac{1707}{539}=3.17 \mathrm{~kg} \\
& \frac{1664}{539}=3.68 \mathrm{~kg}
\end{aligned}
$$

\section{Boiler Efficiency}

The efficiency of the boiler was founded out by the following equation:

$$
\mathrm{q}=\text { ð }(1-\mathrm{w})(1.4 \mathrm{~m}-0.13)+0.5 \text { ð }(\mathrm{t}-32)
$$

\section{Boiler Efficiency on the Basis of Flue Gases Temperature}

At the stack section of the boiler, the flue gas temperature leaving from the boiler ranged between $310{ }^{\circ} \mathrm{F}$ and $330{ }^{\circ} \mathrm{F}$. Hence the average flue gsa value was considered as $320{ }^{\circ} \mathrm{F}$. The values were recorded from the totalizer. Some heat losses from the furnace in the boiler were considered to determine the quantity of the steam that could be obtained from unit weight of bagasse. They are as follows:

a. Latent heat of water(moisture) due to combustion of hydrogen in bagasse.

b. Latent heat of vaporization of water(moisture) in bagasse.

c. Sensible heat lost from the flue gases leaving out of the boiler at stack section.

d. Losses due to non-combusted solids.

e. Radiation losses from furnace.

f. Losses due to incomplete combustion of carbon giving $\mathrm{CO}$ (carbon mono oxide) instead of $\mathrm{CO} 2$ (carbon dioxide).

Out of the six losses mentioned above, latent heat of water and latent heat of vaporization of water have already been considered in Eq.(1) \& Eq.(2) for determining calorific value of bagasse. A considerable loss (c), which remains to be accounted for is the sensible heat lost in the flue gases, which is given by the following equation:

$$
\mathrm{q}=ð(1-\mathrm{w})(1.4 \mathrm{~m}-0.13)+0.5 \partial(\mathrm{t}-32) \text { Eq. (3) }
$$

Where

$\mathrm{q}=$ Sensible heat lost in the flue gases in BTU/lb of bagasse.

$\mathrm{t}=$ Temperature of flue gases at the stack. Its value is taken as $320^{\circ} \mathrm{F}$

$\mathrm{w}=$ Weight of moisture per unit weight of bagasse.

$\mathrm{m}=$ Ratio of weight of actual air required for combustion to weight theoretically necessary. Its value depends on the type of furnace used. For spreader stroker furnace, the excess air required is $50 \%$ of the theoretical air required. Its value is taken as 1.50 .

Substituting these values in Eq. (3)

$$
\begin{aligned}
& q=(1-0.50)(1.4 \times 1.50-0.13)+0.5(320-32) \\
& q=(0.50 \times 1.97+0.5)(288) \\
& q=1.485 \times 288 \\
& q=428 \text { BTU/lb. }
\end{aligned}
$$

The other three losses such as (d) Losses due to noncombusted solids, (e) Radiation losses from furnace, (f) Losses due to incomplete combustion of carbon giving CO (carbon mono oxide) instead of $\mathrm{CO} 2$ (carbon dioxide), were also considered and so the calculation is as follows:

The quantity of remaining heat transferred to steam is given by the expression:

$M v=(7650-2160 s-8730 w-q)$

Where

$ð=$ Co-efficient representing heat loss due to unburnt solids. For spreader stroker furnaces, its normal value is taken as 0.975 .

$\mathrm{P}=$ Co-efficient to account for heat losses by radiation. This value varies from 0.95 to 0.99 for more or less efficient lagging. Its value is taken as 0.97 .

$\tilde{\mathrm{n}}=$ Co-efficient of incomplete combustion. Its value is taken as 0.95 .

$\mathrm{Mv}=$ Heat transferred to steam per pound of bagasse in BTU/lb.

Substituting the values of w, s, q ,ñ,ð\&P

$M v=\tilde{n}(7650-2160 \times 0.03-8730 \times 0.50)-428)$ ð $x 0.975$ x 0.97 x 0.95

$\mathrm{Mv}=(7650-64.80-4365-428) \times 0.898$

$\mathrm{Mv}=2792 \times 0.898$

$\mathrm{Mv}=2507 \mathrm{BTU} / \mathrm{lb}$

Boiler efficiency $=\mathrm{Mv} / \mathrm{N} . \mathrm{C} . \mathrm{V}$

Boiler efficiency $=2507 / 3220$

Boiler efficiency $=77.86 \%$ 


\section{RESULTS AND Discussions}

The results of the calculated values have been compared on the basis of steam obtainable per $\mathrm{Kg}$ of bagasse with $50 \%$ moisture and steam obtainable per $\mathrm{Kg}$ of bagasse with $45 \%$ moisture. The comparisons were tabulated separately to understand the effect of drying the moisture content in the bagasse. Steam obtainable per $\mathrm{Kg}$ of bagasse with $50 \%$ moisture with Increased quantities of $\mathrm{N}_{2}$ and $\mathrm{O}_{2}$ at $50 \%, 75 \%$ and $100 \%$ excess air as follows:

Obtainable Steam Per Kg of Bagasse (50\%)

\begin{tabular}{|c|c|c|c|c|}
\hline \multirow{2}{*}{ Products } & \multicolumn{4}{|c|}{ Excess air } \\
\cline { 2 - 5 } & None & $50 \%$ & $75 \%$ & $100 \%$ \\
\hline $\mathrm{CO}_{2}$ & 1.700 & 1.700 & 1.700 & 1.700 \\
\hline $\mathrm{H}_{2} \mathrm{O}$ & 0.636 & 0.664 & 0.678 & 0.692 \\
\hline $\mathrm{N}_{2}$ & 4.256 & 6.384 & 7.448 & 8.512 \\
\hline $\mathrm{O}_{2}$ & & 0.644 & 0.966 & 1.288 \\
\hline
\end{tabular}

Steam obtainable per $\mathrm{Kg}$ of bagasse with $45 \%$ moisture with Increased quantities of $\mathrm{N}_{2}$ and $\mathrm{O}_{2}$ at $50 \%, 75 \%$ and $100 \%$ excess air as follows:

Obtainable Steam Per Kg of Bagasse (45\%)

\begin{tabular}{|l|l|l|l|l|}
\hline \multirow{2}{*}{ Products } & \multicolumn{4}{|l|}{ Excess air } \\
\cline { 2 - 5 } & None & $50 \%$ & $75 \%$ & $100 \%$ \\
\hline $\mathrm{CO}_{2}$ & 0.940 & 0.940 & 0.940 & 0.940 \\
\hline $\mathrm{H}_{2} \mathrm{O}$ & 0.800 & 0.816 & 0.824 & 0.832 \\
\hline $\mathrm{NO}_{2}$ & 2.360 & 3.534 & 4.122 & 4.712 \\
\hline $\mathrm{O}_{2}$ & & 0.356 & 0.534 & 0.713 \\
\hline
\end{tabular}

TABLE III and TABLE IV shows that moisture reduced bagasse yields higher amount of steam.

\section{A. Taguchi Analysis}

The Taguchi analysis is carried out by considering the data collected from the industry, literature and depending upon the analytical data available.

Taguchi Analysis

\begin{tabular}{|l|l|l|l|l|l|l|l|l|l|}
\hline & \multicolumn{3}{|c|}{ Temperature $\left({ }^{\circ} \mathrm{C}\right)$} & \multicolumn{3}{l|}{ Pressure(MPa) } & \multicolumn{3}{l|}{$\begin{array}{l}\text { Mass Flow } \\
\text { Rate(Kg/s) }\end{array}$} \\
\hline Flow & I & II & III & I & II & III & I & II & III \\
\hline 1 & 38 & 38 & 38 & 1 & 1 & 1 & 26.8 & 24.6 & 24.6 \\
\hline 2 & 77 & 77 & 77 & 1 & 3 & 2 & 18.6 & 18.6 & 18.6 \\
\hline 3 & 32 & 32 & 32 & 1 & 2 & 3 & 97 & 77 & 77 \\
\hline 4 & 258 & 297 & 152 & 1 & 1 & 1 & 97 & 77 & 77 \\
\hline 5 & 500 & 500 & 500 & 74 & 67 & 74 & 62.6 & 62.3 & 62.3 \\
\hline 6 & 401 & 401 & 401 & 71 & 71 & 73 & 62.6 & 62.6 & 62.3 \\
\hline 7 & 262 & 218 & 305 & 65 & 65 & 65 & 7.08 & 6.84 & 6.84 \\
\hline 8 & 168 & 79 & 219 & 65 & 65 & 65 & 121.9 & 99.8 & 99.8 \\
\hline 9 & 175 & 198 & 170 & 66 & 66 & 66 & 121.9 & 99.8 & 99.8 \\
\hline
\end{tabular}

Based on the values obtained using the Taguchi analysis the system is optimized at $500^{\circ} \mathrm{C}$, pressure values ranging from 67MPa-74MPa with a mass flow rate $62.3 \mathrm{Kg} / \mathrm{s}$.

\section{B. Result of Thermal Analysis of Dryer by ANSYS}

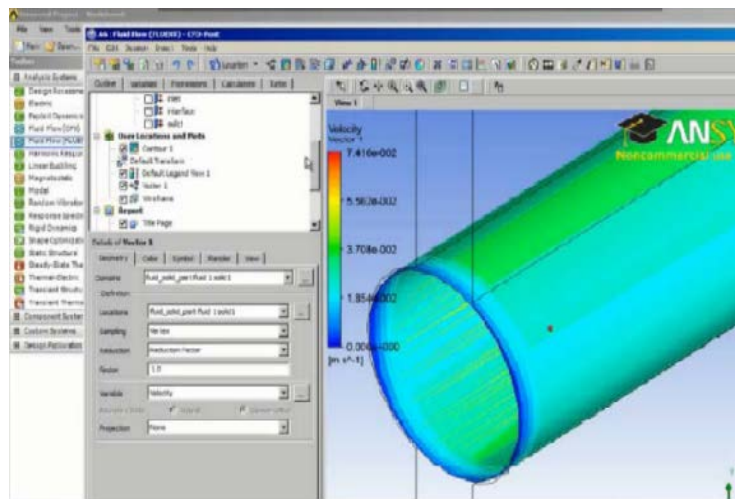

Figure 2: Analysis Report 1

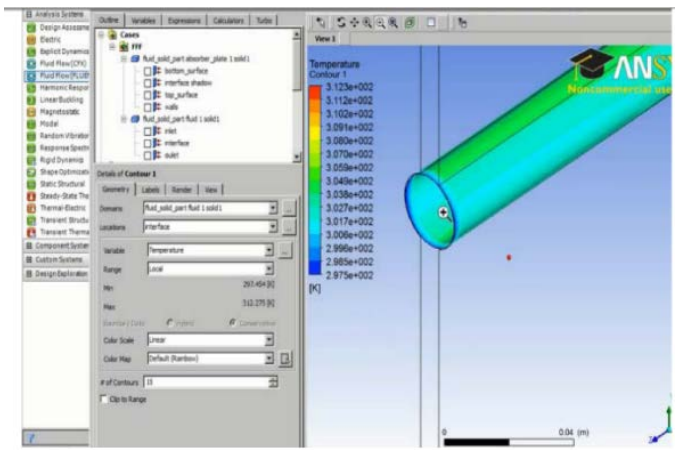

Figure 3: Analysis Report 2

\section{CONCLUSION}

Hence the investigation work shows that the proposed design of the bagasse dryer plays a major role in increasing the boiler efficiency that leads to increased power output.. The calculation shows that there is an increase in boiler efficiency about $77.86 \%$ (about $7 \%$ increase)with the designed dryer and power output has increased up to $5 \%$. It is suggested that further developments in design of dryer will give still better performance of boiler.

\section{REFERENCES}

[1] A.Arrascaeta and P. Friedman, "Bagasse drying: past, present and future”, International Sugar Journal,Vol. 86, No. 1021, Pp. 3-6, 1984.

[2] Augustinsky and Jiri, "Drying of cane bagasse," [Personal Communication].jhsosa@fem.unicamp.br. 01/03/2004.

[3] V.J. Bailliet, "Bagasse drying versus air pre-heating”, The Sugar Journal, Vol. 38, No. 10, Pp. 52-53, 1976.

[4] W.P.Boulet, "Waste fuel Drying and the energy”, The Sugar Journal, Vol. 38, No. 6, Pp. 8-11,1975.

[5] G.Cárdenas, D.De Vasquez and E.Wittwer, "Energy and Exergy analysis of a combined bagasse dryer boiler system”, International Sugar Journal, Vol. 96, No.1146, Pp. 213-219,1994.

[6] M.C. Kinoshita, "Flue Gas Drying of Bagasse”, American Society of Agricultural Engineers, Vol. 91, Pp. 706-729,1991.

[7] F.L. Markezi and S.A. Nebra, "Energetic efficiency maximization of a steam system fueled by sugar cane bagasse”, 17th International Congress of Mechanical Engineering, 2003.

[8] S.A.Nebra, M.A. Silva and A.S. Mujumdar, "Drying in cyclones-a review”, Drying Technology, Vol. 18, No.3, Pp.791-832, 2000.

[9] U.C.Upadhiaya, "Bagasse as a fuel", International Sugar Journal, Vol. 93, No. 1111, Pp. 132-138, 1991. 